Article

\title{
Vibrotactile Stimulation of Nail of Hallux during Walking: Effect on Center-of-Mass Movement in Healthy Young Adults
}

\author{
Haruki Toda $1, *\left(\mathbb{D}\right.$, Yuki Hashimoto ${ }^{2,3}$ and Mitsunori Tada ${ }^{1}$ \\ 1 Digital Human Research Team, Artificial Intelligence Research Center, National Institute of Advanced \\ Industrial Science and Technology, 2-3-26, Aomi, Koto, Tokyo 1350064, Japan; m.tada@aist.go.jp \\ 2 Department of Intelligence Interaction Technology, Tsukuba University, 1-1-1 Tennoudai, Tsukuba, \\ Ibaraki 3058573, Japan; hashimoto@iit.tsukuba.ac.jp \\ 3 JST, PREST, 4-1-8 Honcho, Kawaguchi, Saitama 332-0012, Japan \\ * Correspondence: haruki-toda@aist.go.jp; Tel.: 81-3-3599-8201; Fax: 81-3-5500-5233
}

Received: 25 May 2020; Accepted: 28 June 2020; Published: 30 June 2020

check for updates

Featured Application: The preliminary findings presented in this paper are expected to serve as a foundation for future studies investigating fall prevention in older adults.

\begin{abstract}
Previous studies have reported that vibrotactile stimulation of the nail of the hallux decreases the variability of the center-of-mass (CoM) movement in the lateral direction in subjects performing unsteady walking on the spot. This study investigated the effect of vibrotactile stimulation of the nail of the hallux on the CoM movement during walking. Healthy young males were asked to walk with and without stimulation, and their CoM was measured. The intrasubject mean and coefficient of variation (CV) of their walking speed, stance time, and CoM movement were evaluated. The differences between the variables with and without stimulation were determined, and the baseline-dependent effects of the stimulation on these variables were analyzed. It was observed that stimulation had a negative baseline-dependent effect on the CVs of the walking speed, stance time, and the CoM movement in the lateral direction. In particular, stimulation decreased the CV of the CoM movement in the lateral direction for subjects with a greater variability. Vibrotactile stimulation of the nail of the hallux can reduce the variability of the lateral displacement of the CoM movement in healthy young subjects who otherwise show a large variability of the CoM movement during walking without stimulation.
\end{abstract}

Keywords: vibrotactile stimulation; gait; center-of-mass; variability; rehabilitation; nail of hallux

\section{Introduction}

During human walking, plantar tactile sensation provides somatosensory inputs to the central nervous system as feedback from the plantar surface, thereby making it easier to control balance and walking speed. A temporary reduction in these inputs reduces the walking speed [1] and increases the variability of temporal parameters and lumbar acceleration [2]. In addition, joint kinematics, muscle activity [3,4], and pressure distribution patterns [5] change during walking. Therefore, older adults suffering from sensory deficits caused by diabetic neuropathy have a lower walking speed and greater gait variability than healthy older adults [6].

Vibrotactile stimulation can augment somatosensory feedback during walking. Previous studies found that vibrotactile stimulation could change the stride-to-stride variability of the step width and stride length in the elderly [7], increase the walking speed, single-limb support time, and step length, and significantly decrease the cadence in stroke subjects [8]. In particular, the effect of vibrotactile 
stimulation on the plantar surface is affected by the values obtained without stimulation at the baseline [9]. Thus, this stimulation method provides a baseline-dependent reduction in gait variability for subjects with a more unsteady gait. Vibrotactile stimulation-based interventions could improve walking instability in subjects with sensory deficits.

Previous studies used vibrators embedded at the bottom of insoles or shoes to stimulate the plantar surface [7-10]. Because these devices are integrated in shoes, users have to wear them to be stimulated. However, the plantar skin is thick; therefore, a relatively large stimulation strength is required to transmit vibrations. Furthermore, vibrators cannot be used when walking barefoot and the sensory input from the ground is blocked by the shoe sole and vibrator.

To overcome these problems, Sakai et al. [11-13] proposed a method to generate somatosensory inputs by stimulating the nail of the hallux. Toes have a particularly high distribution density of mechanoreceptors in the plantar region [14]. In addition, the transmission efficiency of vibration is high because a nail is harder than the skin. This method supports daily walking without blocking information from the plantar surface, unlike the technique in which a vibrator is embedded at the bottom of insoles or shoes. In previous studies [11-13], the vibrotactile stimulation of the nail of the hallux increased the stability of the center-of-mass ( $\mathrm{CoM})$ movement while walking on a spot by enhancing the tactile sensation experienced by the foot in healthy young males. On the other hand, one never moves forward while walking on the spot, and it is rarely practiced in daily living. Therefore, it is necessary to verify the effect of vibrotactile stimulation of the nail of the hallux during walking, which is the most frequently performed activity in daily living. However, there are no studies on the effect of the vibrotactile stimulation method on the CoM movement during walking.

The CoM is a theoretical point through which the force of gravity acts on an object [15], and it controls the imbalance and the risk of falls in the elderly [16]. Previous studies investigated the effect of the vibrotactile stimuli on the gait performance, that is, walking speed, cadence, and step length [7-10]. However, the effect of vibrotactile stimulation on the CoM movement is still unclear. If the effect of intervention as a result of using this novel method on the CoM movement during walking is clarified, it can be applied to people with unstable CoM movement, such as older adults and patients with hemiplegia.

This study investigated whether the vibrotactile stimulation of the nail of the hallux affects the CoM movement during walking. A previous study found that vibrotactile stimulation of the plantar surface had a baseline-dependent effect on gait variability and resulted in a greater decrease in variability in subjects with greater baseline variability [9]. We hypothesized that the previous findings of walking on the spot [11-13] are also applicable to walking; in other words, among healthy young people, vibrotactile stimulation of the nail of the hallux is more effective in subjects with a large variability of the CoM movement during walking.

\section{Materials and Methods}

\subsection{Participants}

Thirteen healthy young males (age: $23.8 \pm 1.9$ years, height: $1.69 \pm 0.03 \mathrm{~m}$, weight: $63.9 \pm 7.4 \mathrm{~kg}$, body mass index: $22.1 \pm 2.6 \mathrm{~kg} / \mathrm{m}^{2}$ ) participated in this study. None of the subjects had any history of neuromuscular diseases, trauma, or orthopedic diseases. The dominant leg was determined using the method reported by Schneiders et al. [17], and all the participants in this study were found to be right leg dominant. This study was conducted according to the Declaration of Helsinki [18], and the experimental protocol was approved by the local institutional review board. All the participants gave their written informed consent before the measurements.

\subsection{Vibration System}

Figure 1 shows the vibration system used in this study. The system consists of a vibrator (LD14-002; Nidec Copal Corporation, Tokyo, Japan), a microcontroller (mbed LPC11U24FHI33/301; 
NXP Semiconductors, Eindhoven, the Netherlands), and a pressure sensor (FSR 400 Short; Interlink Electronics, Camarillo, CA, USA). The vibrator was driven using a haptic motor driver (DRV2605; Texas Instruments, Dallas, TX, USA) connected to the microcontroller. When the pressure sensor detects the ground contact of the hallux ball, a sine wave with a frequency of $150 \mathrm{~Hz}$ is immediately generated with negligible time delay. The vibration amplitude was changed using the graphical user interface of a custom-made application running on a Windows tablet.

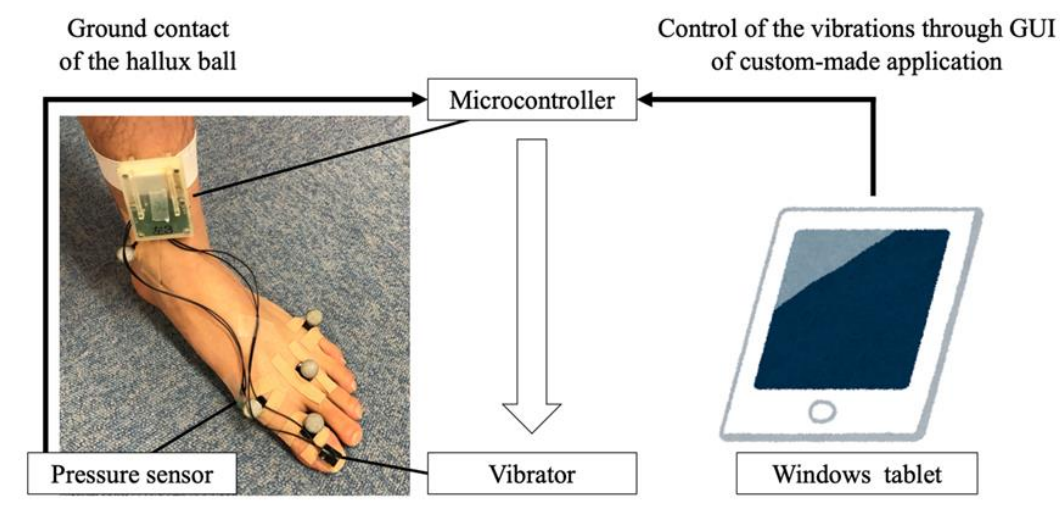

Figure 1. Vibration system used in this study. The vibrator, pressure sensor, and microcontroller were attached on the nail of the hallux, hallux ball, and distal end of the shank, respectively. The vibration was controlled through the graphical user interface of a custom-made application running on a Windows tablet.

\subsection{Experimental Setup}

Fifty-seven infrared reflective markers were placed bilaterally over bony landmarks to measure full-body motion in accordance with a previous study [19]. The vibrators were attached to the both sides of the nail of the hallux using double-sided tape because the hallux is the largest toe of the foot, and the subject could perceive a tactile sensation on the finger pad when this nail was stimulated using vibration [11-13]. The pressure sensors were placed under the hallux ball, and the microcontrollers were attached to the distal end of the shank using a rubber band.

\subsection{Data Collection}

Measurements were recorded in a laboratory with a straight 10-m walkway. A three-dimensional motion analysis system with 15 infrared cameras (Vicon MX and Vicon T, Vicon Motion Systems, Oxford, UK) and nine force plates (BP400600-2000PT, AMTI, Watertown, MA, USA) were used to record the kinematic and kinetic data at sampling frequencies of $200 \mathrm{~Hz}$ and $1000 \mathrm{~Hz}$, respectively (Figure 2).

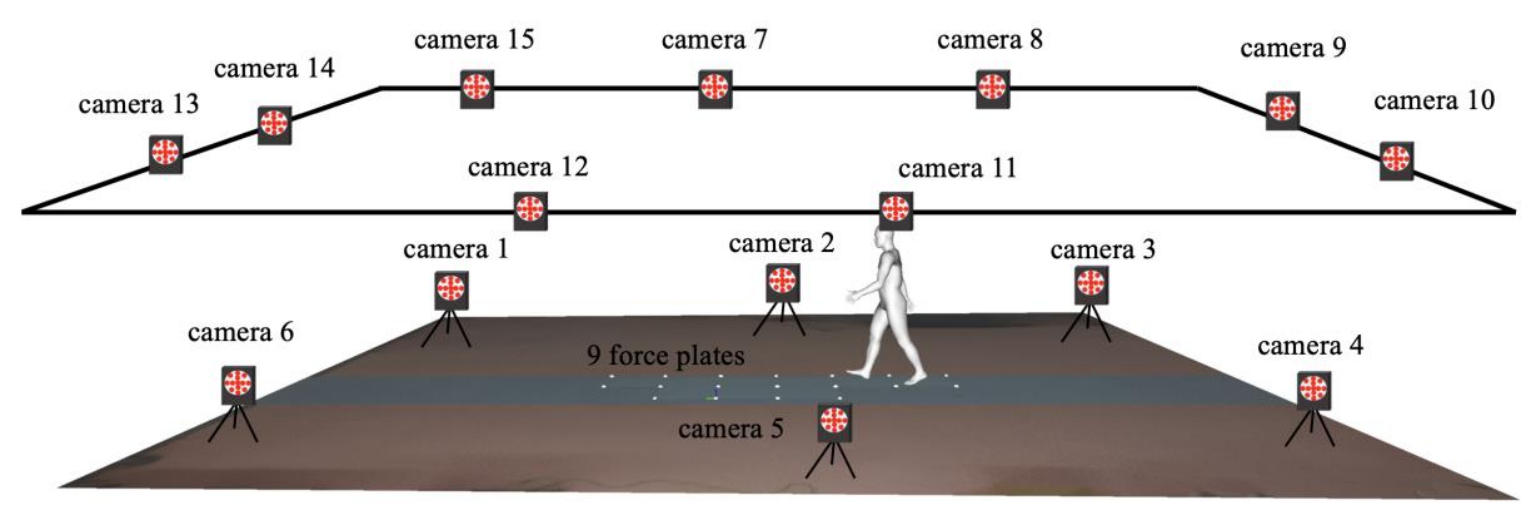

Figure 2. Schematic diagram of a subject during walking and recording of kinematic and kinetic data using a 15-camera motion capture system and nine force plates. 
During the walking trials, all the participants were asked to walk barefoot at a comfortable speed. The participants walked with and without vibrotactile stimulation. The orders of these walking conditions were randomized. The vibration amplitude was adjusted to be as weak as possible so that it was just perceivable to each subject on the finger pad contacting the surface while walking because each individual has a different sensation of the vibration. Before the measurements, the participants walked along the walkway for a few minutes to get accustomed to the environment. Subsequently, five successful trials were conducted where each participant accurately stepped on a force plate.

\subsection{Data Analysis}

The CoM position was calculated using DhaibaWorks-our self-developed motion analysis software [20]. The full-body motion was reconstructed by fitting the marker trajectories and individual body model using a link structure. The dimensions of the body model were estimated statistically using the height and weight of the participant based on a database of Japanese body dimensions [20]. The CoM data were digitally filtered using a fourth-order Butterworth low-pass filter with a cut-off frequency of $10 \mathrm{~Hz}$. The CoM movement during the stance phase of the right limb was extracted based on the ground reaction force data. The amplitudes of the CoM movement in the vertical, progression, and lateral directions during the stance phase were calculated. The walking speed was calculated from the CoM movement in the progression direction of the CoM and the time taken during the stance phase.

The intrasubject mean and standard deviation (SD) values were calculated during the stance phase. Next, the coefficient of variation $(\mathrm{CV}=(\mathrm{SD} /$ mean $) \times 100)$ was calculated as an index of intrasubject variability [21]. The differences between the mean and CV values of the variables obtained with and without stimulation were determined as the effect of stimulation. In addition, to examine the impact of a measurement error, we calculated the minimal detectable change (MDC). The MDC indicates the minimal amount of change that is not likely to be considered a change due to an accidental error in measurement $[22,23]$. First, the standard error of measurement (SEM) was calculated using the SD and intraclass correlation coefficient. Subsequently, the MDC was calculated using the relation: $\mathrm{SEM} \times 1.96 \times \sqrt{ } 2$ [22]. Low-pass filtering and calculation of these variables were performed using MATLAB R2019a (MathWorks Inc., Natick, MA, USA).

\subsection{Statistics}

We conducted the Shapiro-Wilk test to verify normality assumption. Subsequently, because the sample size was small, the differences between the mean and CV values of the CoM movement of the variables obtained with and without stimulation were analyzed by conducting the Wilcoxon signed rank tests, which are nonparametric tests used to analyze the matched-pair data [24]. The baseline-dependent effects of the stimulation were determined by performing the linear regression analysis, and curve regression analysis in case of non-normality. If the relationship between the baseline values and the effect of the stimulation became significant, an additional subgroup analysis was performed. Next, the subjects were divided into two groups based on the value obtained when walking without stimulation-a steady group consisting of six subjects with a small variability, and an unsteady group consisting of six subjects with a large variability, excluding the subject with the median value. Subsequently, the Wilcoxon signed rank test was conducted to examine the difference between the variables obtained with and without stimulation in each group. Values with $p<0.05$ were considered to be statistically significant. All the data were analyzed using SPSS Statistics version 25 (SPSS Inc., Chicago, IL, USA).

\section{Results}

\subsection{Differences Between Variables Obtained with and Without Stimulation}

Table 1 presents the comparison results of the variables obtained with and without stimulation. The walking speed decreased by $3 \%$, and the CoM movement in the progression direction decreased by 
$2 \%$ with vibrotactile stimulation compared with the corresponding values obtained without stimulation. These differences are smaller than the MDC value of each variable. Significant differences were not observed in the values of other variables obtained with and without stimulation.

Table 1. Comparison of variables obtained with and without stimulation (stim).

\begin{tabular}{|c|c|c|c|c|c|c|}
\hline & Variable & & $\begin{array}{l}\text { Without } \\
\text { Stim }\end{array}$ & $\begin{array}{l}\text { With } \\
\text { Stim }\end{array}$ & MDC & $P$-Value \\
\hline \multirow[t]{5}{*}{ Mean } & Walking speed (m/s) & & $1.32 \pm 0.15$ & $1.29 \pm 0.14$ & 0.10 & $0.03 *$ \\
\hline & Stance time (s) & & $0.61 \pm 0.05$ & $0.61 \pm 0.05$ & 0.03 & 0.38 \\
\hline & $\operatorname{CoM}(\mathrm{cm})$ & Vertical & $92.66 \pm 2.49$ & $92.65 \pm 2.46$ & 1.06 & 0.97 \\
\hline & & Progression & $81.22 \pm 6.93$ & $79.42 \pm 7.54$ & 5.69 & $0.02 *$ \\
\hline & & Lateral & $1.92 \pm 0.67$ & $1.75 \pm 0.73$ & 2.17 & 0.97 \\
\hline \multirow[t]{5}{*}{ CV $(\%)$} & Walking speed & & $2.69 \pm 1.28$ & $3.37 \pm 1.65$ & & 0.38 \\
\hline & Stance time & & $1.84 \pm 0.76$ & $2.39 \pm 1.12$ & & 0.15 \\
\hline & CoM & Vertical & $0.35 \pm 0.20$ & $0.36 \pm 0.25$ & & 0.86 \\
\hline & & Progression & $2.48 \pm 0.95$ & $2.61 \pm 1.40$ & & 0.75 \\
\hline & & Lateral & $35.69 \pm 13.00$ & $32.16 \pm 9.81$ & & 0.38 \\
\hline
\end{tabular}

Values: Mean \pm standard deviation. MDC: Minimal detectable change. *: Statistically significant difference between values with and without stimulation $(p<0.05)$.

\subsection{Baseline-Dependent Effect of Vibrotactile Stimulation}

In terms of the mean value, although the CoM movements in the progression and lateral directions were analyzed by performing the curve regression analysis and the linear regression analysis, the results of the curve regression analysis were not statistically significant ( $p=0.898$ and 0.158 , respectively). Therefore, only the linear regression analysis results are presented in Table 2 and Figure 3. The effect of stimulation on the $\mathrm{CV}$ values of the walking speed, stance time, and CoM movement in the lateral direction depends on the $\mathrm{CV}$ values obtained when walking without the stimulation. The negative baseline-dependent effect of these variables indicates that the differences between the CV values decreased linearly as the values of the variable increased. Therefore, the subjects were divided into the steady and unsteady groups for each of these variables, and the subjects in these group were different depending on each variable. A comparison of the results of these groups indicates that the CV values of the walking speed and stance time increased in the steady group as a result of stimulation, as shown in Figure $4 \mathrm{a}, \mathrm{b}$, respectively. On the other hand, the CV of the CoM movement in the lateral direction decreased in the unsteady group (Figure $4 \mathrm{c}$ ).

Table 2. Linear regression analysis results showing the effects of values obtained without stimulation and changes in values due to stimulation.

\begin{tabular}{|c|c|c|c|c|c|c|}
\hline & Variable & & $\begin{array}{c}\text { Unstandardized } \\
\text { Coefficients }(95 \% \mathrm{CI})\end{array}$ & $\begin{array}{l}\text { Standardized } \\
\text { Coefficients }\end{array}$ & Adjusted $R^{2}$ & $P$-Value \\
\hline \multirow[t]{5}{*}{ Mean } & Walking speed & & $-0.10(-0.36$ to 0.15$)$ & -0.27 & 0.01 & 0.38 \\
\hline & Stance time & & $-0.01(-0.22$ to 0.18$)$ & -0.06 & 0.08 & 0.84 \\
\hline & CoM & Vertical & $-0.02(-0.09$ to 0.05$)$ & -0.18 & 0.05 & 0.56 \\
\hline & & Progression & $-0.02(-0.34$ to 0.29$)$ & -0.05 & 0.08 & 0.84 \\
\hline & & Lateral & $-0.63(-1.32$ to 0.05$)$ & -0.52 & 0.21 & 0.06 \\
\hline \multirow[t]{5}{*}{$\mathrm{CV}$} & Walking speed & & $-1.23(-2.08$ to -0.39$)$ & -0.70 & 0.44 & 0.008 * \\
\hline & Stance time & & $-1.44(-2.37$ to 0.52$)$ & -0.71 & 0.47 & $0.006^{*}$ \\
\hline & CoM & Vertical & $-0.01(-0.52$ to 0.49$)$ & -0.02 & 0.09 & 0.95 \\
\hline & & Progression & $-0.64(-1.59$ to 0.30$)$ & -0.41 & 0.09 & 0.16 \\
\hline & & Lateral & $-0.87(-1.36$ to -0.37$)$ & -0.76 & 0.54 & 0.003 * \\
\hline
\end{tabular}


(a)

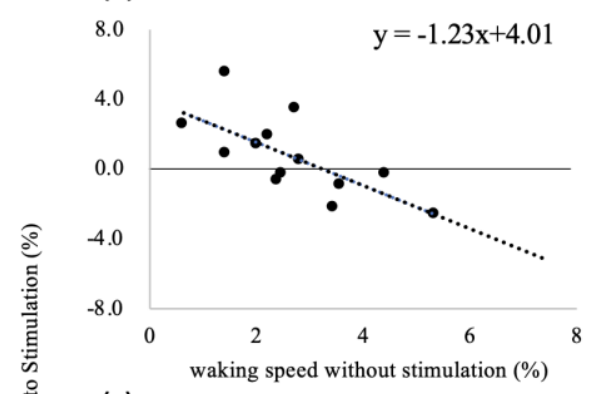

(c)

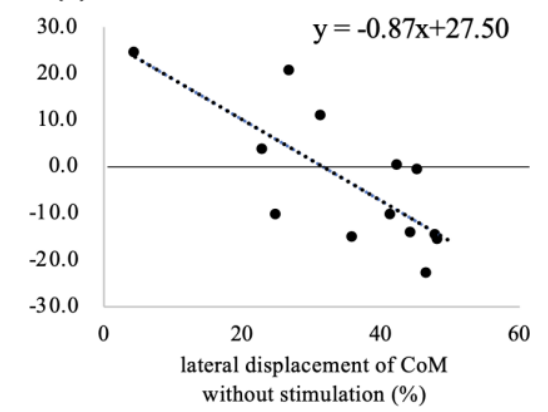

(b)

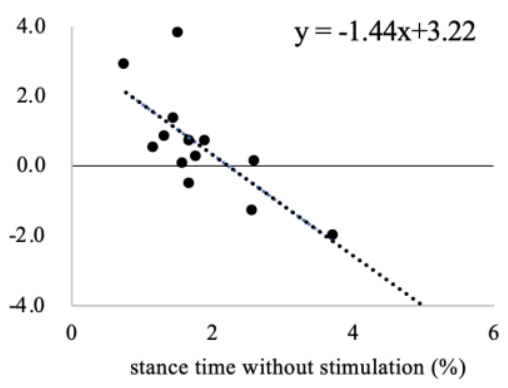

Figure 3. Relationship between the coefficient of variation (CV) without vibrotactile stimulation and changes due to stimulation for (a) walking speed, (b) stance time, and (c) center-of-mass (CoM) movement in the lateral direction.

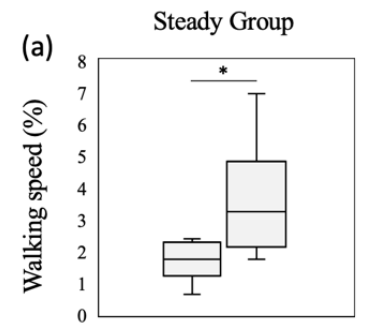

Unsteady Group
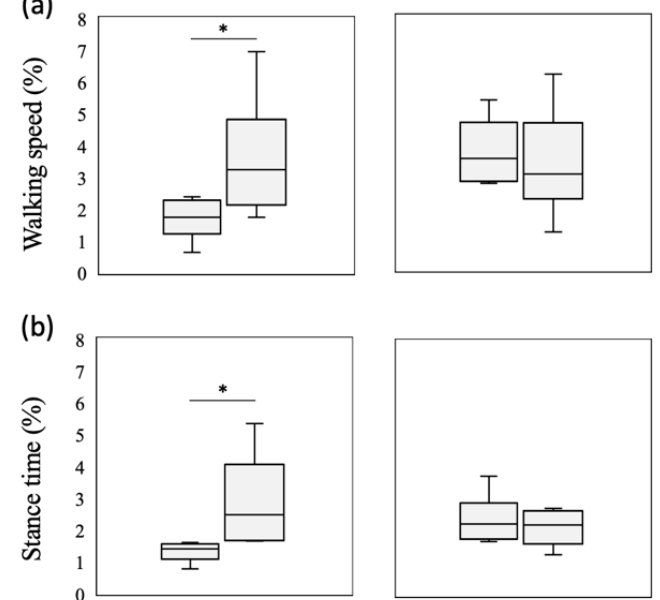

(b)

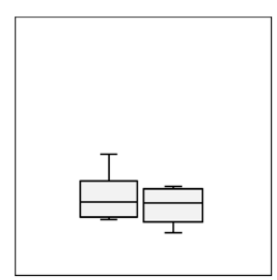

(c)
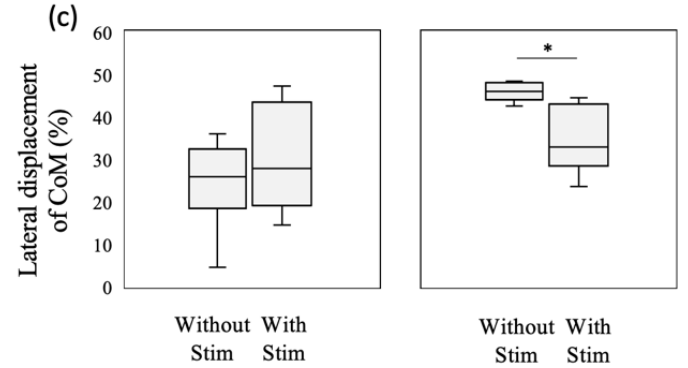

Figure 4. Box plots of CV for (a) walking speed, (b) stance time, and (c) CoM movement in the lateral direction with and without vibrotactile stimulation for the steady $(n=6)$ and unsteady $(n=6)$ groups. The box indicates the interquartile range. The horizontal and vertical lines indicate the median and the range of the maximum and minimum values, respectively. * indicates significant differences between values obtained with and without stimulation at $p<0.05$. 


\section{Discussion}

This study examined the effect of vibrotactile stimulation of the nail of the hallux on the CoM movement during the stance phase. The proposed method had a baseline-dependent effect on the variability of the CoM movement and was more effective for subjects with a large variability of the $\mathrm{CoM}$ movement in the lateral direction during walking. Stimulation did not affect the amplitude of the CoM movement. These results support our hypothesis. This study highlighted the effect of the novel method in which vibrotactile stimulation was applied to the nail of the hallux to the variability of the CoM movement during walking in healthy young people.

As shown in Figure 3, the effect of vibrotactile stimulation of the nail of the hallux depends on the variability of the walking speed, stance time, and the CoM movement in the lateral direction at the baseline. Stimulation decreased the fluctuations in these variables for subjects exhibiting a large intrasubject variability when walking without the stimulation. This result is in good agreement with that of a previous study that examined the effect of stimulation of the plantar surface [9]. In particular, stimulation was remarkably effective for subjects with a large variability of the CoM movement in the lateral direction (Figure 4c). The CoM movement in the lateral direction is associated with walking stability $[15,25]$. In addition, a large walking variability is considered indicative of poor walking stability [26]. The lateral movement of walking was actively controlled using the feedback control [27]. We speculated that vibrotactile stimulation of the nail of the hallux could enhance the tactile sensation perceived by the foot. In addition, the stimulation was likely to put the attention of the participant on the foot by suprathreshold stimulation. Attention has an impact on the control of non-automated motion [28]. Therefore, by using this stimulation method, the CoM movement in the lateral direction during walking was stabilized for subjects with unsteady movement, in the same manner as in previous studies that achieved stabilization while walking on the spot [11-13]. In previous studies [6,29,30], older adults were found to have greater walking variability during walking compared to young people. Thus, vibrotactile stimulation of the nail of the hallux might be useful in reducing the variability of the CoM movement in the elderly.

In contrast, stimulation increased he variabilities of the walking speed and stance time in the steady group, as shown in Figure $4 a, b$, respectively. The sensory feedback from the foot contributes to the cyclical gait patterns produced by neural rhythm generators in the central nervous system [31]. We speculated that the feedback system of the subject in the steady group was already working when walking without stimulation. However, by applying the stimulation to such a subject using vibration, the cyclical gait patterns may be disrupted. Therefore, the variabilities of these variables, including the temporal aspect of gait, increased in the steady group as a result of stimulation.

The walking speed decreased with the CoM movement in the progression direction because of the stimulation (Table 1). However, the values of these variables decreased by only a few percent and were smaller than the MDC values in this study. The MDC is the minimal amount of change that is not likely to be considered a change due to a measurement error [22]. Thus, these differences were caused by a measurement error and were not sufficient to show the effect of stimulation. Consequently, vibrotactile stimulation did not affect the amount of the CoM movement during walking in healthy young people. These results suggest that the vibrotactile stimulation of the nail of the hallux is more likely to affect the variability of the CoM movement than with the amount of the CoM movement.

The present study also has some limitations. First, a relatively small sample size of young people was considered, based on the before-after design. Therefore, to clarify the effect of this stimulation method on walking stability in the elderly, further studies should to be conducted using a randomized controlled trial with a larger sample size, including older adults. Second, a previous study reported that there are gender differences in biomechanical gait parameters [32]. Therefore, only male participants were considered in this study to eliminate the effects of gender differences. To elucidate the gender-specific effect, further studies are necessary to examine the effect of this stimulation method on walking in female subjects during walking. Third, the stimulation amplitude was set to a suprathreshold level and was adjusted to be as weak as possible by tuning it for each subject. 
The differences in the magnitude and frequency of vibration, including supra- and subthreshold values, affected the stride-to-stride fluctuations in the stride length and interval [10]. In addition, no consensus was reached on the effect of the differences between vibrating devices or the duration and magnitude of the stimulation on gait parameters [33]. In particular, older adults have an age-related decline in the sensorimotor and/or cognitive function [6]. In a future study, we intend to investigate the optimal setting of the vibration applied to the nail of the hallux considering the age of the subjects. Furthermore, in this study, the effectiveness of the proposed method could not be compared with that of the conventional method that stimulated the plantar surface because the subjects may feel uncomfortable while attaching the vibrator to the plantar skin and walking barefoot. In the future, we will consider fabricating shoes for the experiments to avoid discomfort and to compare the effects of both the proposed and the conventional methods. Finally, the lateral control of walking was achieved using hip abductor muscles [34]. Analysis of the kinetics and muscle activity of this muscle may be useful to verify the effect of the vibration stimulation on the lateral displacement of the CoM.

\section{Conclusions}

This study examined the effect of vibrotactile stimulation of the nail of the hallux on the CoM movement during walking in young people. Stimulation of the nail of the hallux had baseline-dependent effects on the variability of the walking speed, stance time, and the CoM movement in the lateral direction during the stance phase. Among healthy young males, the proposed stimulation method was more effective in those with a large variability of the CoM movement in the lateral direction during walking. These preliminary findings can serve as a foundation for future studies on the variability of gait in older adults. Further studies are required to clarify the effect of the proposed stimulation method on the walking stability in older adults.

Author Contributions: Conceptualization, H.T. and Y.H.; methodology, H.T.; software, Y.H.; validation, H.T., Y.H. and M.T.; formal analysis, H.T.; investigation, H.T.; resources, Y.H.; data curation, H.T.; writing-original draft preparation, H.T.; writing-review and editing, Y.H. and M.T.; visualization, H.T.; supervision, M.T.; project administration, M.T.; funding acquisition, H.T., Y.H., and M.T. All authors have read and agreed to the published version of the manuscript.

Funding: This research was funded by the JSPS Grant-in-Aid for Young Scientist (19K19860), JST AIP-PRISM (JPMJCR18Y2), and JST PRESTO (JPMJPR 17J7).

Acknowledgments: We would like to thank Editage (www.editage.com) for English language editing.

Conflicts of Interest: The authors declare no conflict of interest.

\section{References}

1. Taylor, A.J.; Menz, H.B.; Keenan, A.M. Effects of experimentally induced plantar insensitivity on forces and pressures under the foot during normal walking. Gait Posture 2004, 20, 232-237. [CrossRef]

2. Sawa, R.; Doi, T.; Misu, S.; Tsutsumimoto, K.; Fujino, H.; Ono, R. Decreased skin temperature of the foot increases gait variability in healthy young adults. Gait Posture 2013, 38, 518-522. [CrossRef]

3. Eils, E.; Behrens, S.; Mers, O.; Thorwesten, L.; Völker, K.; Rosenbaum, D. Reduced plantar sensation causes a cautious walking pattern. Gait Posture 2004, 20, 54-60. [CrossRef]

4. Hohne, A.; Ali, S.; Stark, C.; Bruggemann, G.P. Reduced plantar cutaneous sensation modifies gait dynamics, lower-limb kinematics and muscle activity during walking. Eur. J. Appl. Physiol. 2012, 112, 3829-3838. [CrossRef] [PubMed]

5. $\quad$ Eils, E.; Nolte, S.; Tewes, M.; Thorwesten, L.; Völker, K.; Rosenbaum, D. Modified pressure distribution patterns in walking following reduction of plantar sensation. J. Biomech. 2002, 35, 1307-1313. [CrossRef]

6. Menz, H.B.; Lord, S.R.; St George, R.; Fitzpatrick, R.C. Walking stability and sensorimotor function in older people with diabetic peripheral neuropathy. Arch. Phys. Med. Rehabil. 2004, 85, 245-252. [CrossRef] [PubMed]

7. Novak, P.; Novak, V. Effect of step-synchronized vibration stimulation of soles on gait in Parkinson's disease: A pilot study. J. Neuroeng. Rehabil. 2006, 3, 9. [CrossRef] [PubMed] 
8. Lee, S.W.; Cho, K.H.; Lee, W.H. Effect of a local vibration stimulus training programme on postural sway and gait in chronic stroke patients: A randomized controlled trial. Clin. Rehabil. 2013, 27, 921-931. [CrossRef]

9. Stephen, D.G.; Wilcox, B.J.; Niemi, J.B.; Franz, J.R.; Kerrigan, D.; D'Andrea, S.E. Baseline-dependent effect of noise-enhanced insoles on gait variability in healthy elderly walkers. Gait Posture 2012, 36, 537-540. [CrossRef]

10. Chien, J.H.; Ambati, V.N.P.; Huang, C.K.; Mukherjee, M. Tactile stimuli affect long-range correlations of stride interval and stride length differently during walking. Exp. Brain Res. 2017, 235, 1185-1193. [CrossRef]

11. Sakai, K.; Hachisu, T.; Hashimoto, Y. Characteristics of illusory vibration in the toe pad induced by vibration applied to toenail and toe force to surface. In Proceedings of the 2017 IEEE World Haptics Conference (WHC), Munich, Germany, 5-9 June 2017; pp. 281-286. [CrossRef]

12. Sakai, K.; Hachisu, T.; Hashimoto, Y. Sole tactile display using tactile illusion by vibration on toenail. In Haptic Interaction, Lecture Notes in Electrical Engineering, Proceedings of the International Asia Haptics Conference, Kashiwa, Japan, 29 November-1 December 2016; Hasegawa, S., Konyo, M., Kyung, K.U., Nojima, T., Kajimoto, H., Eds.; Springer: Singapore, 2016; Volume 432, pp. 95-97. [CrossRef]

13. Sakai, K.; Hashimoto, Y. Perceptual characteristics of a tactile illusion using toenail-mounted vibration. In Proceedings of the ICAT-EGVE 2015, Kyoto, Japan, 28-30 October 2015; p. 10.

14. Hennig, E.M.; Sterzing, T. Sensitivity mapping of the human foot: Thresholds at 30 skin locations. Foot Ankle Int. 2009, 30, 986-991. [CrossRef] [PubMed]

15. Mackinnon, C.D.; Winter, D.A. Control of whole body balance in the frontal plane during human walking. J. Biomech. 1993, 26, 633-644. [CrossRef]

16. Fujimoto, M.; Chou, L.S. Sagittal plane momentum control during walking in elderly fallers. Gait Posture 2016, 45, 121-126. [CrossRef] [PubMed]

17. Schneiders, A.G.; Sullivan, S.J.; O’Malley, K.J.; Clarke, S.V.; Knappstein, S.A.; Taylor, L.J. A valid and reliable clinical determination of footedness. PMER 2010, 2, 835-841. [CrossRef]

18. World Medical Association General Assembly. World medical association declaration of helsinki. JAMA 2013, 310, 2191-2194. [CrossRef] [PubMed]

19. Kobayashi, Y.; Ogata, T. Association between the gait pattern characteristics of older people and their two-step test scores. BMC Geriatr. 2018, 18, 101. [CrossRef] [PubMed]

20. Endo, Y.; Tada, M.; Mochimaru, M. Dhaiba: Development of virtual ergonomic assessment system with human models. In Proceedings of the 3rd International Digital Human Modeling Symposium, Tokyo, Japan, 20-22 May 2014.

21. Kobayashi, Y.; Hobara, H.; Matsushita, S.; Mochimaru, M. Key joint kinematic characteristics of the gait of fallers identified by principal component analysis. J. Biomech. 2014, 47, 2424-2429. [CrossRef]

22. Andreopoulou, G.; Mahad, D.J.; Mercer, T.H.; Van Der Linden, M.L. Test-retest reliability and minimal detectable change of ankle kinematics and spatiotemporal parameters in MS population. Gait Posture 2019, 74, 218-222. [CrossRef]

23. Haley, S.M.; Fragala-Pinkham, M.A. Interpreting change scores of tests and measures used in physical therapy. Phys. Ther. 2006, 86, 735-743. [CrossRef]

24. Woolson, R.F. Wilcoxon signed-rank test. In Wiley Encyclopedia of Clinical Trials; John Wiley \& Sons, Inc.: Hoboken, NJ, USA, 2007; pp. 1-3. [CrossRef]

25. Rogers, M.W.; Mille, M.-L. Lateral stability and falls in older people. Exerc. Sport Sci. Rev. 2003, 31, $182-187$. [CrossRef]

26. Pieruccini-Faria, F.; Montero-Odasso, M.; Hausdorff, J.M. Gait variability and fall risk in older adults: The role of cognitive function. In Falls and Cognition in Older Persons; Montero-Odasso, M., Camicioli, R., Eds.; Springer: Cham, Switzerland, 2019; pp. 107-138. [CrossRef]

27. Bauby, C.E.; Kuo, A.D. Active control of lateral balance in human walking. J. Biomech. 2000, 33, $1433-1440$. [CrossRef]

28. Beilock, S.L.; Carr, T.H.; MacMahon, C.; Starkes, J.L. When paying attention becomes counterproductive: Impact of divided versus skill-focused attention on novice and experienced performance of sensorimotor skills. J. Exp. Psychol. Appl. 2002, 8, 6-16. [CrossRef]

29. Moe-Nilssen, R.; Helbostad, J.L. Interstride trunk acceleration variability but not step width variability can differentiate between fit and frail older adults. Gait Posture 2005, 21, 164-170. [CrossRef] [PubMed]

30. Gabell, A.; Nayak, U. The effect of age on variability in gait. J. Gerontol. 1984, 39, 662-666. [CrossRef] 
31. Taga, G.; Yamaguchi, Y.; Shimizu, H. Self-organized control of bipedal locomotion by neural oscillators in unpredictable environment. Biol. Cybern. 1991, 65, 147-159. [CrossRef] [PubMed]

32. Kerrigan, D.C.; Todd, M.K.; Croce, U.D. Gender differences in joint biomechanics during walking; Normative study in young adults. Am. J. Phys. Med. Rehabil. 1998, 77, 2-7. [CrossRef] [PubMed]

33. Aboutorabi, A.; Arazpour, M.; Bahramizadeh, M.; Farahmand, F.; Fadayevatan, R. Effect of vibration on postural control and gait of elderly subjects: A systematic review. Aging Clin. Exp. Res. 2018, 30, 713-726. [CrossRef] [PubMed]

34. Pandy, M.G.; Lin, Y.-C.; Kim, H.J. Muscle coordination of mediolateral balance in normal walking. J. Biomech. 2010, 43, 2055-2064. [CrossRef] [PubMed]

(C) 2020 by the authors. Licensee MDPI, Basel, Switzerland. This article is an open access article distributed under the terms and conditions of the Creative Commons Attribution (CC BY) license (http://creativecommons.org/licenses/by/4.0/). 